\title{
Characterisation of major component leaching and buffering capacity of RDF incineration and gasification bottom ash in relation to reuse or disposal scenarios
}

\author{
Stefania Rocca ${ }^{a}$, André van Zomeren ${ }^{\text {b }}$, Giulia Costa ${ }^{\mathrm{a}, *}$, Joris J. Dijkstra ${ }^{\mathrm{b}}$, Rob N.J. Comans ${ }^{\text {b,c }}$, \\ Francesco Lombardi ${ }^{a}$ \\ a University of Rome “Tor Vergata”, Department of Civil Engineering, Via del Politecnico 1, 00133 Rome, Italy \\ ${ }^{\mathrm{b}}$ Energy Research Centre of the Netherlands (ECN), Department of Environmental Risk Assessment, P.O. Box 1, 1755 ZG Petten, The Netherlands \\ ${ }^{c}$ Wageningen University, Department of Soil Quality, P.O. Box 47, 6700 AA Wageningen, The Netherlands
}

\section{A R T I C L E I N F O}

\section{Article history:}

Received 7 June 2011

Accepted 28 November 2011

Available online 9 January 2012

\section{Keywords:}

Bottom ash

Gasification

Geochemical modelling

Incineration

Leaching

Refuse derived fuel

\begin{abstract}
A B S T R A C T
Thermal treatment of refuse derived fuel (RDF) in waste-to-energy (WtE) plants is considered a promising solution to reduce waste volumes for disposal, while improving material and energy recovery from waste. Incineration is commonly applied for the energetic valorisation of RDF, although RDF gasification has also gained acceptance in recent years. In this study we focused on the environmental properties of bottom ash (BA) from an RDF incineration (RDF-I, operating temperature $850-1000^{\circ} \mathrm{C}$ ) and a RDF gasification plant (RDF-G, operating temperature $1200-1400^{\circ} \mathrm{C}$ ), by evaluating the total composition, mineralogy, buffering capacity, leaching behaviour (both at the material's own $\mathrm{pH}$ and as a function of $\mathrm{pH}$ ) of both types of slag. In addition, buffering capacity results and pH-dependence leaching concentrations of major components obtained for both types of BA were analysed by geochemical modelling. Experimental results showed that the total content of major components for the two types of BA was fairly similar and possibly related to the characteristics of the RDF feedstock. However, significant differences in the contents of trace metals and salts were observed for the two BA samples as a result of the different operating conditions (i.e. temperature) adopted by the two RDF thermal treatment plants. Mineralogy analysis showed in fact that the RDF-I slag consisted of an assemblage of several crystalline phases while the RDF-G slag was mainly made up by amorphous glassy phases. The leached concentrations of major components (e.g. $\mathrm{Ca}, \mathrm{Si}$ ) at the natural $\mathrm{pH}$ of each type of slag did not reflect their total contents as a result of the partial solubility of the minerals in which these components were chemically bound. In addition, comparison of total contents with leached concentrations of minor elements (e.g. $\mathrm{Pb}, \mathrm{Cu}$ ) showed no obvious relationship for the two types of BA. According to the compliance leaching test results, the RDF-G BA would meet the limits of the Italian legislation for reuse and the European acceptance criteria for inert waste landfilling. RDF-I BA instead would meet the European acceptance criteria for non hazardous waste landfilling. A new geochemical modelling approach was followed in order to predict the leaching behaviour of major components and the $\mathrm{pH}$ buffering capacity of the two types of slags on the basis of independent mineralogical information obtained by XRD analysis and the bulk composition of the slag. It was found that the combined use of data regarding the mineralogical characterization and the buffering capacity of the slag material can provide an independent estimate of both the identity and the amount of minerals that contribute to the leaching process. This new modelling approach suggests that only a limited amount of the mineral phases that control the $\mathrm{pH}$, buffering capacity and major component leaching from the solid samples is available for leaching, at least on the time scale of the applied standard leaching tests. As such, the presented approach can contribute to gain insights for the identification of the types and amounts of minerals that control the leaching properties and pH buffering capacity of solid residues such as RDF incineration and gasification bottom ash.
\end{abstract}

(c) 2011 Elsevier Ltd. All rights reserved.

\section{Introduction}

Thermal treatment of municipal solid waste (MSW) in wasteto-energy (WtE) plants is one of the essential components of the

\footnotetext{
* Corresponding author. Tel.: +39 06 72597039; fax: +39 0672597021

E-mail address: costa@ing.uniroma2.it (G. Costa).
}

integrated waste management strategies currently adopted by most developed countries. In this context, thermal treatment of specifically processed MSW in order to increase its homogeneity and calorific value and thus denominated refuse derived fuel (RDF), is being progressively applied with the aim of increasing energy recovery and employ technologies characterized by a lower environmental impact (Dalai et al., 2009; Bosmans and Helsen, 
2010). RDF is produced by sorting, size and weight-based separation and shredding of commingled MSW. It is therefore characterized by a relatively constant size distribution and composition, mainly consisting of high caloric waste fractions like paper and cardboard (50-60\% wt.), plastics (20-30\% wt.), along with textiles and rubber (10-15\% wt.). Therefore, thermal treatment of this type of waste can lead to quite stable operating conditions (treatment temperature in particular), as well as a more homogenous quality of the resulting gas products as compared to MSW (Consonni et al., 2005; Bosmans and Helsen, 2010) and hence may allow to employ more advanced technologies than those adopted for WtE treatment of commingled waste. Currently, thermal treatment of RDF in dedicated plants, or together with MSW in co-combustion facilities, is applied in 17 of the 53 thermal treatment plants in operation in Italy (ISPRA, 2009). Following the indications of recent environmental legislation to favour technologies that allow to reduce the volumes of waste for final disposal while enhancing material and energy recovery, the treatment capacities of WtE plants employing RDF are expected to increase in the future, especially in Italy and in other European countries such as Germany, as indicated by Haker et al. (2010). Incineration in water-cooled grate combustors at temperatures around $850-1000{ }^{\circ} \mathrm{C}$ with air, which is the most adopted technology for WtE treatment of MSW, is commonly applied also for the energetic valorisation of RDF (Jannelli and Minutillo, 2007). On the other hand, in recent years, RDF gasification in a high temperature $\left(1200-1400^{\circ} \mathrm{C}\right)$ fluidized bed reactor applying sub-stoichiometric oxygen concentrations, has also gained acceptance due to its higher potential energy recovery efficiency and lower production of NOx and SOx emissions compared to incineration (Belgiorno et al., 2003; Bosmans and Helsen, 2010; Castaldi and Themelis, 2010). However, as reported by Giugliano et al. (2008), higher operating costs must be considered for this advanced waste management technology.

Regardless of the type of thermal treatment technology adopted, WtE plants generate a number of solid by-products, among which the most abundant is bottom ash (BA), which accounts generally for $10-20 \%$ wt. of the feedstock (e.g. Polettini, 2009). In many European countries (e.g. Denmark, The Netherlands and France) the reuse of BA from MSW incineration (MSWI) plants as an aggregate substitute for natural materials in construction applications is commonly practiced if the residues present suitable technical properties. In other countries BA is generally landfilled as a non hazardous waste as there is no specific legislation regulating its utilization conditions. More information on the current status of BA management practices in the EU may be found in the literature (see e.g. Polettini, 2009).

However, given the non negligible content of potentially toxic components such as metals in this type of material, concerns exist whether the reuse of BA may exert adverse environmental effects. Therefore, several studies have extensively addressed the leaching behaviour of contaminants from MSWI BA when reused as a secondary construction material, for both short and long term scenarios (e.g. Dijkstra et al., 2002; Kosson et al., 2002; Ecke and Aberg, 2006).

As a result of the quite recent development of RDF thermal treatment technologies, relatively few studies have focused up to now on the technical and environmental properties of RDF incineration and gasification BA. Beneficial utilization of RDF incineration $\mathrm{BA}$ as a fine aggregate in concrete, cement blends or in landfill cover construction seems to be feasible from a technical point of view, as high compressive strength has been observed for this residue in specific application scenarios (Chang et al. 1999; Onori et al., 2011). Although there is no comprehensive study on the leaching behaviour of these types of BA, Travar et al. (2009) have indicated relatively high leaching concentrations of soluble salts $\left(\mathrm{Cl}^{-}\right.$and $\mathrm{SO}_{4}^{2-}$ ) from RDF incineration bottom ash, while Baciocchi et al.
(2010) indicated $\mathrm{Pb}, \mathrm{Cr}$ and $\mathrm{Cu}$ as the most critical contaminants leached from freshly quenched RDF incineration BA. The physical and geotechnical characteristics of RDF gasification BA have been also indicated as suitable for reuse in specific applications, as e.g. in road constructions. However, recent studies regarding the leaching behaviour of fresh and weathered gasification BA showed that $\mathrm{Cu}, \mathrm{Cr}$, Mo and Ni concentrations may hinder the reuse of this type of thermal treatment residues (Sivula et al., 2010; Gori et al., 2011). Anyhow, it should be noted that there is little information on the fundamental physical and chemical mechanisms that control the leaching behaviour of the BA produced from either type of RDF thermal treatment technology.

The purpose of this paper is to assess and compare the environmental properties of RDF incineration and gasification BA on the basis of their total composition, mineralogy, leaching of major components as a function of $\mathrm{pH}$ and buffering capacity. It is well known in fact, that these properties play an important role in determining the leaching behaviour of a material in a specific application scenario and should, hence, be attentively examined before focusing on the leaching concentrations of trace contaminants (Meima and Comans, 1997). The long-term pH development of BA in a specific scenario depends in fact on the buffering capacity of the slag matrix, which is in turn determined by its mineralogy (Johnson et al., 1995). In addition to the leaching properties of major components, the leaching of trace elements at the natural $\mathrm{pH}$ of the slags was also analyzed and the results were compared with regulatory limits for disposal or re-use, as a first indication for evaluating the reusability of the two types of BA. The leaching mechanisms involved in the release of minor elements will be addressed instead in a following paper. It is believed in fact that a fundamental study on the environmental properties of bottom ash generated from specific RDF thermal treatment technologies is necessary for establishing environmentally and economically sound management practices.

\section{Materials and methods}

\subsection{Bottom ash sample preparation}

About $100 \mathrm{~kg}$ of freshly quenched BA were sampled from two thermal treatment plants: (1) a RDF incinerator (RDF-I) equipped with a grate-type combustion chamber and (2) a RDF gasification plant (RDF-G) equipped with a high temperature gasifying and direct melting reactor. The two types of BA were homogenized through a quartering procedure following a standardized methodology (Italian norm UNI 10802:2004), in order to obtain representative samples for the experimental analyses. Coarse metallic and ceramic fragments $(d>5 \mathrm{~cm})$ were manually removed. The BA was oven-dried at $60^{\circ} \mathrm{C}$ to constant weight and sieved in order to analyze its grain size distribution. From this analysis, the fraction presenting a grain size ranging from 0.425 to $12 \mathrm{~mm}$, making up more than $90 \%$ wt. of both types of slag, was selected as the most representative in terms of grain size and employed for the subsequent analysis. In addition, characterization analysis performed on the fraction with $d<0.425 \mathrm{~mm}$ (results not shown) indicated that there were no substantial differences in the main properties and specifically in the leaching behaviour of these samples compared to the $0.425-12 \mathrm{~mm}$ size fraction.

\subsection{Composition analysis}

The characterization of the main composition of the two types of BA included the determination of the loss on ignition, total organic carbon content, bulk concentration of major and trace com- 
ponents, carbonate content and mineralogical composition of each material.

The loss on ignition (LOI) at $1000^{\circ} \mathrm{C}$ was evaluated following the ASTM C25 procedure. The Total Organic Carbon (TOC) content of the BA samples was measured with a TOC-5000A Shimadzu analyzer. The bulk chemical composition of each type of BA was obtained after lithium tetraborate digestion of the slag samples at $1050{ }^{\circ} \mathrm{C}$ and dissolution of the molten material in a $10 \% \mathrm{HNO}_{3}$ solution. The total content of major ( $\mathrm{Ca}, \mathrm{Si}, \mathrm{Al}, \mathrm{Mg}, \mathrm{Na}, \mathrm{Fe}, \mathrm{K}$ and $\mathrm{Mn}$ ) and trace elements, including metals ( $\mathrm{Zn}, \mathrm{Cu}, \mathrm{Pb}, \mathrm{Ni}$ and $\mathrm{Cd}$ ) and oxyanion-forming metalloids $(\mathrm{Cr}$, Mo, $\mathrm{Sb}$, As and $\mathrm{V}$ ) were determined by atomic absorption spectroscopy (AAS), employing a Perkin Elmer AAS equipped with a graphite furnace and a hydride generation system, or alternatively by inductively coupled plasma atomic emission spectroscopy (ICP-AES). The BA contents of chlorides $\left(\mathrm{Cl}^{-}\right)$and acid soluble sulfates $\left(\mathrm{SO}_{4}^{2-}\right)$ were measured respectively by dissolution of the samples with hot deionised water and titration of the resulting solutions with $\mathrm{AgNO}_{3}$, and by dissolution of the samples with $3 \% \mathrm{HCl}$ solutions followed by spectrophotometric analysis of the produced solutions. The carbonate $\left(\mathrm{CO}_{3}^{2-}\right)$ content of the slag was investigated using a Dietrich-Frülingh calcimeter, which involved acidification $(\mathrm{HCl})$ of the samples and subsequent measurement of the evolved gas volume. All the measurements were carried out in triplicate. The qualitative mineralogical characterization of the two types of BA was determined by X-ray powder diffraction (XRD) analysis using a Philips Expert Pro diffractometer equipped with a copper tube operated at $40 \mathrm{kV}$ and $40 \mathrm{~mA}$. Diffraction patterns were collected over a 2 Theta range from 5 to $85^{\circ}$, employing an angular step of $0.02^{\circ}$ and a count time of $2 \mathrm{~s}$.

\subsection{Leaching experiments}

To evaluate the potential release of main and trace components from the two types of BA, related to disposal or secondary material reuse scenarios, a combination of different characterisation and compliance leaching tests were employed. A batch compliance leaching test at the material's own $\mathrm{pH}$ was carried out according to the European standard EN 12457-2. In short, BA with a particle size reduced to below $4 \mathrm{~mm}$ was leached with distilled water at a liquid to solid (L/S) ratio of $10 \mathrm{l} / \mathrm{kg}$, under continuous stirring for $24 \mathrm{~h}$. After measuring the $\mathrm{pH}$ of the solutions, these were filtered through $0.45 \mu \mathrm{m}$ pore size filters and eluate concentrations of different inorganic contaminants were determined by AAS and ICPAES. In addition, leachate concentrations of $\mathrm{Cl}^{-}$and $\mathrm{SO}_{4}^{2-}$ were analysed by titration with $\mathrm{AgNO}_{3}$ and spectrophotometric analysis, respectively. The dissolved organic carbon (DOC) content of the obtained solutions was measured with a Shimadzu TOC-V CPH analyzer. Eluate concentrations of specific elements were compared with the limit values established for inert waste landfilling reported in Annex II of the European Landfill Directive (2003/33/ EC). In addition, leachate concentrations were compared with the limits set by the Italian legislation for the reuse of non hazardous waste (Italian Environmental Ministry, 1998), although these limits currently do not specifically apply to BA from WtE plants. Leaching tests were carried out in duplicate.

The $\mathrm{pH}$ dependence leaching test was performed according to the CEN/TS 14429 standard procedure on the two types of BA for $\mathrm{pH}$ values ranging from 2 to 12.5 . In short, analytical-grade nitric acid $\left(\mathrm{HNO}_{3}\right)$ or sodium hydroxide $(\mathrm{NaOH})$ was used to adjust the $\mathrm{pH}$ in parallel batch leaching tests. Each suspension was equilibrated at a final $\mathrm{L} / \mathrm{S}$ ratio of $10 \mathrm{l} / \mathrm{kg}$ for $48 \mathrm{~h}$ and after measuring its final $\mathrm{pH}$ value, was filtered through $0.45 \mu \mathrm{m}$ pore size filters and subsequently analysed by AAS and ICP-AES, of which only the concentrations of major elements are reported and discussed in this study. $\mathrm{Cl}^{-}$and $\mathrm{SO}_{4}^{2-}$ concentrations were also analysed using the same methods adopted for the batch compliance leaching tests.

\subsection{Geochemical modelling of major components}

In this work we focused on understanding the leaching behaviour of the major components $\left(\mathrm{Ca}, \mathrm{Si}, \mathrm{Mg}, \mathrm{Al}, \mathrm{Fe}, \mathrm{SO}_{4}^{2-}\right.$ and $\mathrm{CO}_{3}^{2-}$ ) of both types of BA. Previous studies on MSWI BA have demonstrated in fact that these substances play a major role in governing leachate pH (e.g. Meima and Comans, 1997; Dijkstra et al., 2008). The modelling approach is largely similar to that described in Dijkstra et al. (2008) to which the reader is referred for details. In short, the measured total contents of major components were used as initial estimates for the reactive amounts of elements needed as input for the speciation modelling framework ORCHESTRA (Meussen, 2003) included in the LeachXS database/expert system (http:// www.leachxs.com/lxsdll.html). The XRD results obtained in the present study were used as a starting point to select the set of mineral phases to take into account in the modelling approach. Where considered appropriate, based on the results of previous studies regarding MSWI BA (e.g. Dijkstra et al., 2006), other mineral phases were also considered, as indicated below. Unless noted otherwise, equilibrium mineral solubility and solution speciation was calculated using thermodynamic data from the MINTEQA2 3.11 database and subsequent additions/corrections made in previous publications (Allison et al., 1991; Dijkstra et al, 2008 and references therein).

\section{Results and discussions}

\subsection{Bottom ash composition}

Table 1 shows the results of the total chemical composition for the RDF-I and the RDF-G bottom ashes. The LOI at $1000^{\circ} \mathrm{C}$ measured for the RDF-I BA corresponded to about $5 \%$ wt., which was mainly associated to inorganic phases, since TOC analysis showed that only $0.35 \%$ wt. of the samples could be associated to unburned

\section{Table 1}

Bulk chemical composition for the RDF-I BA and the RDF-G BA. Data are presented as mean values \pm standard deviation.

\begin{tabular}{|c|c|c|}
\hline & RDF-I BA & RDF-G BA \\
\hline \multicolumn{3}{|c|}{ Values (\%) \pm s.d. (abs. v.) } \\
\hline LOI & $5.1 \pm 0.2$ & $<0.01$ \\
\hline TOC & $0.35 \pm 0$ & $0.02 \pm 0$ \\
\hline \multicolumn{3}{|c|}{ Major components: concentration (g/kg d.m.) \pm s.d. (abs. v.) } \\
\hline $\mathrm{Ca}$ & $258.4 \pm 6.1$ & $227.9 \pm 21.5$ \\
\hline $\mathrm{Si}$ & $205.4 \pm 6.6$ & $154.2 \pm 26.4$ \\
\hline $\mathrm{Al}$ & $63.5 \pm 3$ & $137.6 \pm 5.9$ \\
\hline $\mathrm{Mg}$ & $19.1 \pm 0.8$ & $12.9 \pm 1.2$ \\
\hline $\mathrm{Na}$ & $54.2 \pm 0.9$ & $4.6 \pm 0.1$ \\
\hline $\mathrm{Fe}$ & $26.8 \pm 1.2$ & $6.7 \pm 1.6$ \\
\hline K & $4.2 \pm 0$ & $0.5 \pm 0.02$ \\
\hline $\mathrm{Cl}^{-}$ & $48.7 \pm 2.6$ & $0.6 \pm 0.1$ \\
\hline $\mathrm{SO}_{4}^{2-}$ & $2.4 \pm 0.1$ & $0.4 \pm 0.03$ \\
\hline $\mathrm{CO}_{3}^{2-}$ & $103.3 \pm 5.8$ & $<0.5$ \\
\hline \multicolumn{3}{|c|}{ Trace elements: concentration ( $\mathrm{mg} / \mathrm{kg}$ d.m.) \pm s.d. (abs. v.) } \\
\hline $\mathrm{Zn}$ & $4209.6 \pm 121.2$ & $44.4 \pm 11.3$ \\
\hline $\mathrm{Cu}$ & $3848.2 \pm 417.9$ & $1158.6 \pm 237.4$ \\
\hline $\mathrm{Pb}$ & $986.9 \pm 111.7$ & $21.4 \pm 3.8$ \\
\hline Mn & $530.1 \pm 37.6$ & $322.4 \pm 7.2$ \\
\hline $\mathrm{Cr}$ & $326 \pm 14.4$ & $1441.9 \pm 38.7$ \\
\hline $\mathrm{Ni}$ & $141.8 \pm 16.5$ & $162.9 \pm 62.2$ \\
\hline $\mathrm{Sb}$ & $133.6 \pm 6$ & $1.3 \pm 0.3$ \\
\hline Mo & $26.6 \pm 2.8$ & $<0.5$ \\
\hline As & $4.6 \pm 0.5$ & $1.2 \pm 0.2$ \\
\hline V & $2.2 \pm 0.6$ & $<1.5$ \\
\hline $\mathrm{Cd}$ & $<0.02$ & $<0.02$ \\
\hline
\end{tabular}


organic matter. No LOI or TOC was detected instead for the RDF-G $\mathrm{BA}$, due to the type of thermal treatment applied in the plant (melting at $1200-1400{ }^{\circ} \mathrm{C}$ ).

Regarding the elemental composition of the two types of $\mathrm{BA}$, the results exhibited in Table 1 show that the total content of major components such as $\mathrm{Ca}, \mathrm{Si}, \mathrm{Al}$ and $\mathrm{Mg}$ was fairly similar, indicating that the concentration of these elements in the slag depends chiefly on the characteristics of the feed waste, which in both cases was RDF. These results are in good agreement with those of Rendek et al. (2007) that demonstrated that the quality of the waste input to MSW incineration plants significantly affected the bulk content of major elements in the resulting BA. Significant differences in the elemental composition of the two types of BA were however observed for inorganic carbon, salts-forming components ( $\mathrm{Na}, \mathrm{K}, \mathrm{Cl}^{-}$ and $\mathrm{SO}_{4}^{2-}$ ), metals (mainly $\mathrm{Zn}$ and $\mathrm{Pb}$ ), as well as oxyanion forming metalloids ( $\mathrm{Sb}$ and $\mathrm{Mo}$ ). The RDF-I BA showed to be relatively enriched in the above mentioned phases compared to the RDF-G BA with concentration values of at least 1 or 2 orders of magnitude higher, probably owing to the operating temperature adopted in the second type of plant that possibly increased the volatilization of elements such as e.g. $\mathrm{Zn}, \mathrm{Pb}$ and $\mathrm{Sb}$. In this perspective, the process technology applied for the thermal treatment of RDF appeared to exert a great influence on BA quality. A significantly (about a factor of 5) higher concentration of $\mathrm{Cr}$ was measured instead in the RDF-G BA compared to the RDF-I BA. This result might be correlated to the partial deterioration of the refractory material coating the gasification reactor walls which, as reported by plant personnel, contains chromium oxides. Overall, the bulk chemical composition of major components ( $\mathrm{Ca}, \mathrm{Si}$ and $\mathrm{Mg}$ ) and trace contaminants $(\mathrm{Pb}, \mathrm{Cu}$ and $\mathrm{Zn}$ ) for the two samples showed a good agreement with the data reported in previous studies regarding bottom ash originated from RDF incineration (Travar et al., 2009; Baciocchi et al., 2010) and gasification plants (Gori et al., 2011).

Qualitative mineralogical characterization of the BA by XRD analysis revealed that the RDF-I BA contained a variety of crystalline phases (Fig. 1a). The most intense diffraction peaks corresponded to gehlenite $\left(\mathrm{G}\right.$ : $\left.\mathrm{Ca}_{2} \mathrm{Al}_{2} \mathrm{SiO}_{7}\right)$ and calcite $\left(\mathrm{C}\right.$ : $\left.\mathrm{CaCO}_{3}\right)$. The presence of the latter component is consistent with direct measurement of $\mathrm{CO}_{3}^{2-}$ (see Table 1 ) and could have been originated from the partial natural carbonation of the hydrated Ca-bearing phases during the storage of this type of BA; the following hydrated phases were in fact detected in RDF-I BA: hydrocalumite ( $\left.\mathrm{H}: \mathrm{Ca}_{4} \mathrm{Al}_{2} \mathrm{Cl}_{2} \mathrm{O}_{6} \cdot 10 \mathrm{H}_{2} \mathrm{O}\right)$ and portlandite $\left(\mathrm{Ca}: \mathrm{Ca}(\mathrm{OH})_{2}\right)$. A significant content of several silica-containing phases, namely: quartz $(\mathrm{Q}$ : $\mathrm{SiO}_{2}$ ), anorthite $\left(\mathrm{An}: \mathrm{CaAl}_{2} \mathrm{Si}_{2} \mathrm{O}_{8}\right)$ and akermanite $\left(\mathrm{Ak}: \mathrm{Ca}_{2} \mathrm{MgSi}_{2} \mathrm{O}_{7}\right)$, as well as hematite ( $\mathrm{He}: \mathrm{Fe}_{2} \mathrm{O}_{3}$ ) were also identified by XRD analysis. The main crystalline phases detected in this study were also reported by Baciocchi et al. (2010) for different size fractions of the same type of BA. The XRD diffractogram for RDF-G BA showed a consistent amorphous glassy matrix which was deduced from the evident hump in the diffractogram measured in the 2 Theta range from 10 to 40 (Fig. 1 b). Therefore, only a few crystalline phases were identified in this type of BA, namely akermanite and magnetite $\left(\mathrm{M}: \mathrm{Fe}_{3} \mathrm{O}_{4}\right)$. These results are consistent with those of Gori et al. (2011) which also indicated the prevalence of glassy phases in gasification BA.

\subsection{Leaching characterisation at natural $\mathrm{pH}$}

The $\mathrm{pH}$ values of the two types of BA determined from the batch compliance leaching test were significantly different: 12.4 for RDFI BA and 10.3 for RDF-G BA. The alkaline $\mathrm{pH}$ resulting for RDF-I BA was correlated to its higher Ca-leaching (about 2 orders of magnitude) compared to RDF-G BA (Fig. 2 a), which might indicate (near) equilibrium dissolution of portlandite $\left(\mathrm{Ca}(\mathrm{OH})_{2}\right)$ at $\mathrm{pH}>12$ (Meima and Comans, 1997; Polettini and Pomi, 2004). Hence, although, as shown in Table 1, the total Ca content of the two types of BA was similar, Ca leaching concentrations varied considerably owing to the different mineralogy of the two types of slag.

In addition, higher concentrations of salts-forming components $\left(\mathrm{Na}, \mathrm{K}, \mathrm{Cl}^{-}\right.$), metals (mostly $\mathrm{Pb}, \mathrm{Cu}$ and $\mathrm{Zn}$ ), as well as oxyanionic metalloids (mainly $\mathrm{Sb}$ and $\mathrm{Mo}$ ) were measured in the eluates of RDF-I BA compared to those of RDF-G BA. The higher leaching of salts-forming components was directly correlated to their total content in the first type of BA (see Table 1), as also indicated (for $\mathrm{Cl}^{-}$in particular) in previous studies on MSWI BA (Rendek et al., 2007; Hyks and Astrup, 2009). In the case of more reactive elements, e.g. $\mathrm{Pb}, \mathrm{Cu}$ and $\mathrm{Zn}$, comparison of total contents (exhibited in Table 1) with leaching concentrations showed no obvious correlations for the two types of BA. As will be investigated further below, differences in the leaching concentrations of these metals for the two types of slag were probably also due to the different natural $\mathrm{pH}$ of the samples, since the solubility of these elements is strongly dependent on $\mathrm{pH}$, as indicated in previous studies on MSWI BA (e.g. Meima and Comans, 1997). The leached concentrations of $\mathrm{Pb}, \mathrm{Cu}$ and $\mathrm{Zn}$ reported by Travar et al. (2009) for RDF-I BA were at least 1 order of magnitude lower compared to our results for the same type of BA. These differences can possibly be related to the lower $\mathrm{pH}$ (10.2) of the slag tested in the previous study, which was partly aged upon 1 year exposure to the atmosphere. In general, in fact, ageing and reduction of a very alkaline $\mathrm{pH}$ value result in a lower leaching of the above mentioned contaminants that present an amphoteric behaviour(e.g. Chimenos et al., 2003; Dijkstra et al., 2006; Hyks and Astrup, 2009). However, to confirm this hypothesis, $\mathrm{pH}$-dependent leaching analysis of these relatively new materials is required.

The leaching results determined at the natural $\mathrm{pH}$ of the two types of BA were compared with the European acceptance criteria for inert waste landfilling (2003/33/EC) and the Italian limits for the reuse of non hazardous waste (Italian Environmental Ministry,
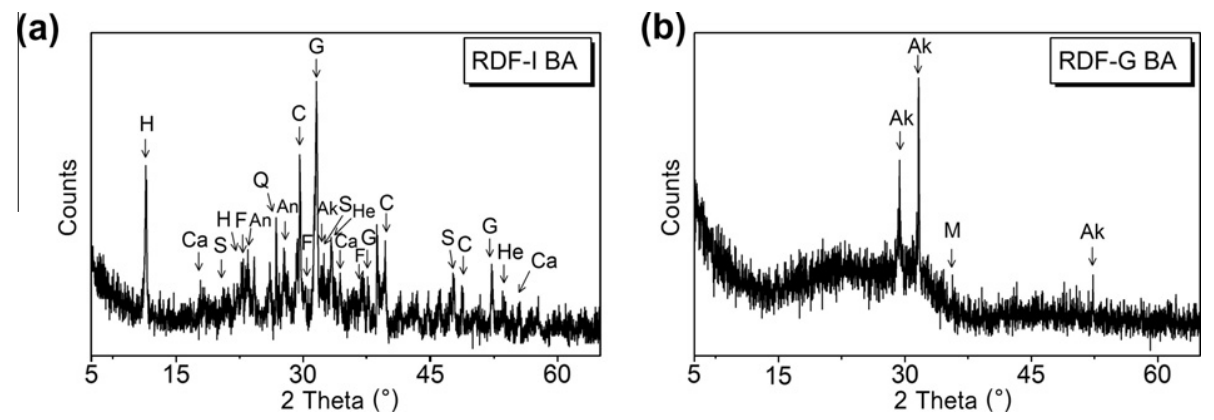

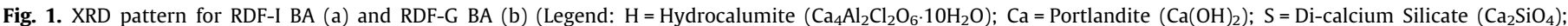

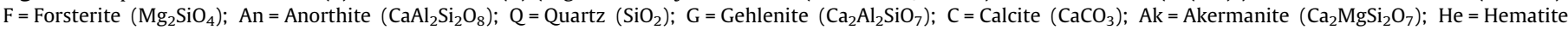
$\left(\mathrm{Fe}_{2} \mathrm{O}_{3}\right) ; \mathrm{M}=$ Magnetite $\left(\mathrm{Fe}_{3} \mathrm{O}_{4}\right)$ ) 
(a)

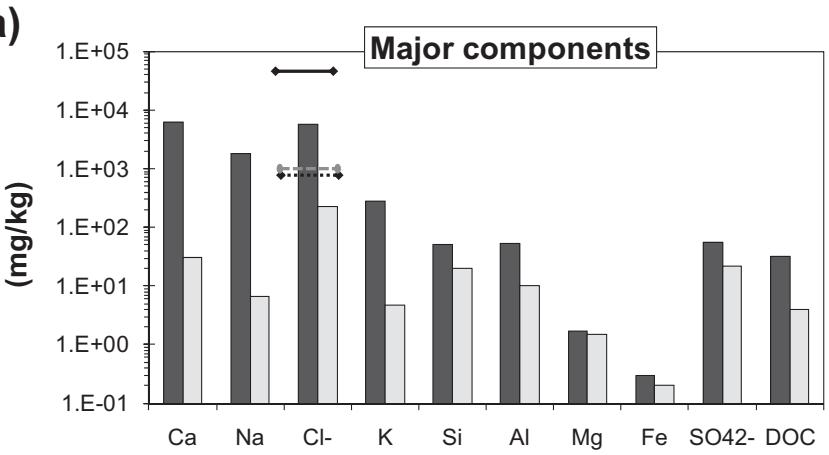

(b)

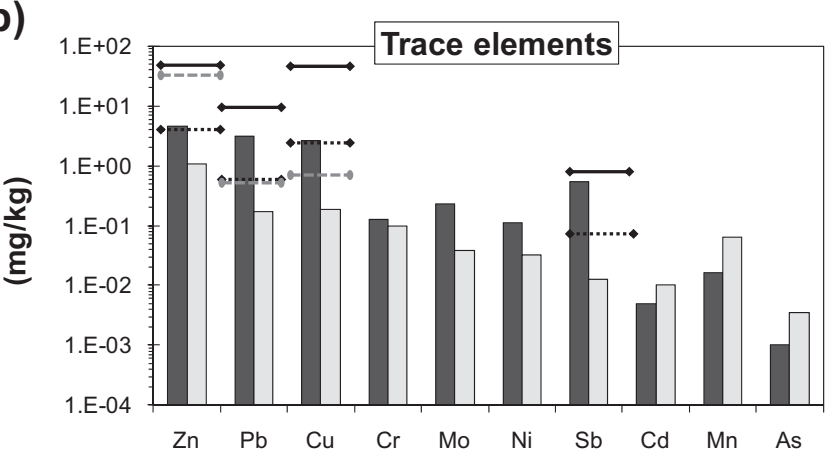

Fig. 2. Leaching test (EN 12457-2) results of major components (a) and trace elements (b) for RDF-I BA $(\mathrm{pH}=12.4)$ and RDF-G BA $(\mathrm{pH}=10.3)$. The acceptance criteria for inert waste landfilling (inert LFD) and non-hazardous waste landfilling (non-hazardous LFD), as well as Italian requirements for reuse (reuse) are also reported when relevant.

1998). From this comparison it emerged that RDF-G BA would meet both the Italian legislation requirements for reuse and the European acceptance criteria for inert waste landfilling. RDF-I BA instead would meet the requirements for non hazardous waste landfilling, since eluate concentrations of $\mathrm{Cl}^{-}, \mathrm{Zn}, \mathrm{Pb}, \mathrm{Cu}$, and $\mathrm{Sb}$ exceeded the European acceptance criteria for inert waste landfilling (Fig. 2). Furthermore, for RDF-I BA samples eluate concentrations of $\mathrm{Cl}^{-}, \mathrm{Pb}$ and $\mathrm{Cu}$ resulted above the Italian limits for reuse.

It should be noted however, that the results of the compliance leaching tests are not able to reproduce the complete picture of the emissions related to a real landfill or reuse scenario, as released concentrations vary over time and are influenced by key factors such as the $\mathrm{L} / \mathrm{S}$ ratio and $\mathrm{pH}$. To assess the long-term environmental emissions of these types of materials in any type of application, $\mathrm{pH}$ development is an important parameter to investigate because it may exert important consequences in terms of emissions of contaminants. In addition, as previously mentioned, the solubility of the major mineral phases involved in the leaching process is linked to the acid neutralization capacity of the material. For these reasons and in order to provide a more fundamental characterization of the slag materials, $\mathrm{pH}$ dependent leaching tests and associated geochemical modelling of major component chemistry was also performed.

\section{3. pH-dependence leaching characterisation}

\subsubsection{Acid/base neutralization capacity}

The ANC/BNC curves derived from the $\mathrm{pH}$-dependence leaching test are shown in Fig. 3. The two types of BA displayed a remarkable

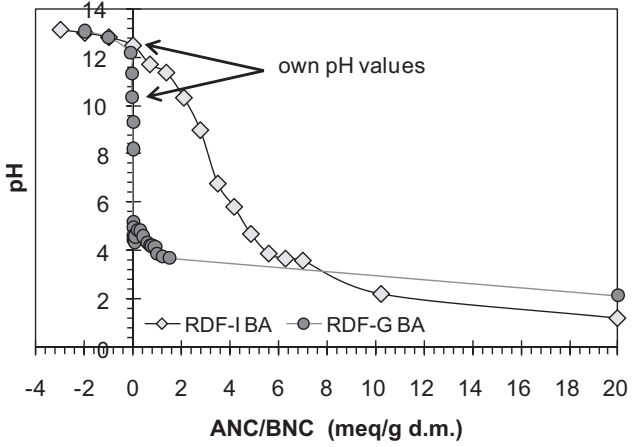

Fig. 3. Acid/base neutralization capacity (ANC/BNC) curves for RDF-I BA and RDF-G BA samples.

difference in the acid neutralization capacity below $\mathrm{pH} 12$, which may be attributed to their different mineralogical composition, as indicated by the results of XRD analysis (see Fig. 1).

An increase in acid addition corresponded to a gradual decrease of the $\mathrm{pH}$ of the eluates of RDF-I BA from values above 12 to 4 , with a total acid buffering capacity of about 6 meq $\mathrm{H}^{+} / \mathrm{g} \mathrm{d}$.m. These results were ascribed to the significant content of hydrated phases, such as calcium hydroxide and hydrocalumite, calcium silicatecontaining phases, as well as of calcium carbonate/bicarbonate detected for this type of slag by XRD analysis. A similar ANC behaviour was found in a previous study on the same type of RDF incineration BA (Baciocchi et al., 2010).

For the RDF-G BA instead, the addition of a small amount of nitric acid $\left(<0.01 \mathrm{meq} \mathrm{H}^{+} / \mathrm{g} \mathrm{d}\right.$.m.) resulted in a rapid drop of the $\mathrm{pH}$ of the eluates (from 12 to 5 ) followed by an extensive buffering capacity at $\mathrm{pH}$ values between 3 and 4 . 5 . This behaviour was correlated to the mineralogy of the slag, characterized by a lack of (rapidly soluble) alkaline crystalline phases and a predominance of amorphous glassy phases that are typically characterized by a buffering capacity at $\mathrm{pH} 4$. These results proved consistent with those reported by Gori et al. (2011).

This finding is highly relevant, as the pH of MSWI BA has generally been indicated to be buffered at alkaline $\mathrm{pH}$ field-site conditions due to its content of mineralogical phases such as ettringite and calcite (Meima and Comans, 1997). From the above discussed results, however, RDF-G BA, may be expected to exhibit a different behaviour due to its negligible acid buffering capacity, resulting in a decrease of $\mathrm{pH}$ to values of 7 or lower, induced by the conditions imposed by the local environment (e.g. for rainwater $\mathrm{pH} 5-6$; for soils $\mathrm{pH} 3$ to 8; Lindsay, 1979), with possible consequences on the leaching behaviour of the slag. The solubility of many contaminants, such as amphoteric metals for example, increases considerably at $\mathrm{pH}$ values below 6 , hence, to evaluate the leaching behaviour of RDF-G BA in an application scenario, it may be more correct to consider the eluate concentrations obtained at acidic $\mathrm{pH}$ values instead of those resulting at the natural $\mathrm{pH}$ of the material.

\subsection{2. $p H$-dependent leaching properties of major components}

As a possible result of the different mineralogical composition and ANC of the two types of BA, differences were observed in the $\mathrm{pH}$-dependent leaching curves of $\mathrm{Ca}, \mathrm{Si}, \mathrm{Mg}, \mathrm{Al}, \mathrm{Fe}$ and $\mathrm{SO}_{4}^{2-}$, reported in Fig. 4. As a reference, in Fig. 4 also the mean, upper and lower 95\% confidence interval limits obtained from a compiled dataset contained in the LeachXS database/expert system based on leaching concentrations of 15 samples of MSWI BA of worldwide origin are reported. MSWI bottom ash is an important reference material since extensive information on the leaching behaviour of this type of ash is currently available (e.g. Dijkstra et al., 2006). The graphical comparison reported in Fig. 4 is believed to 

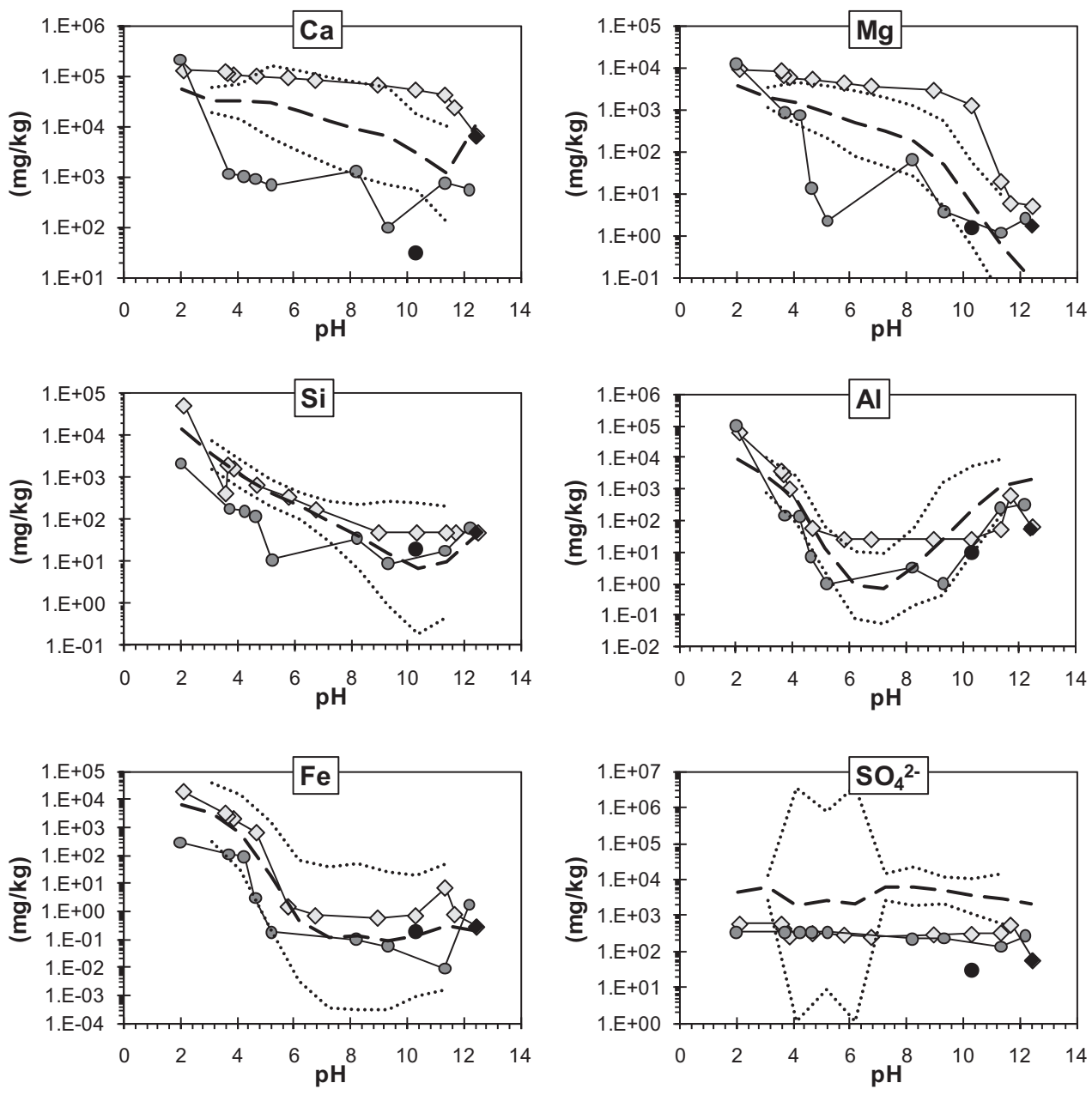

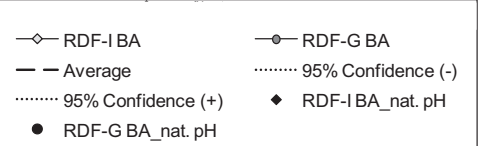

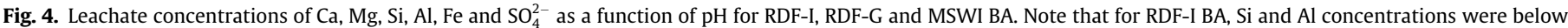
the detection limits in the $\mathrm{pH}$ range 9-11.7 and 6.7-10, respectively.

provide a valuable way to evaluate whether the leaching properties of RDF BA are similar or differ significantly from those of MSWI $\mathrm{BA}$. The results of the compliance leaching test at the natural $\mathrm{pH}$ of the two samples are also included in the graphs as single points, in order to evaluate if these concentrations match those derived from the $\mathrm{pH}$ dependent leaching test.

The differences between the leaching behaviour of RDF-I and RDF-G BA are evident for $\mathrm{Ca}, \mathrm{Mg}, \mathrm{Si}, \mathrm{Fe}$ and to a lesser extent for $\mathrm{Al}$ and $\mathrm{SO}_{4}^{2-}$. In particular, RDF-I BA exhibited significantly higher leaching concentrations of $\mathrm{Ca}$ and $\mathrm{Mg}$ compared to the average values obtained for MSWI BA, whereas RDF-G BA showed a much lower release of these elements. The leaching curves of $\mathrm{Si}, \mathrm{Fe}$ and $\mathrm{Al}$ obtained for RDF-I BA were quite similar to those determined for MSWI BA, while lower concentrations were measured for RDF-G $\mathrm{BA} . \mathrm{SO}_{4}^{2-}$ concentrations for both $\mathrm{RDF}$ incineration and gasification BA samples were roughly 1 order of magnitude lower than those of average MSWI BA samples in the entire $\mathrm{pH}$ range considered.

In general, leaching results obtained with the EN 12457-2 test at the natural $\mathrm{pH}$ for the two BA samples showed a good match with those derived from the $\mathrm{pH}$ dependence leaching tests at a corresponding $\mathrm{pH}$ value, although lower $\mathrm{Ca}$ and $\mathrm{SO}_{4}^{2-}$ concentrations were measured for the RDF-G BA in the batch test at natural $\mathrm{pH}$.
These differences are probably related to the slower leaching kinetics of these particular components from the glassy RDF-G samples, since for the $\mathrm{pH}$ dependence leaching tests a longer equilibration time was applied ( $48 \mathrm{~h}$ instead of $24 \mathrm{~h}$ ).

\subsection{Geochemical modelling of major components}

Based on the above discussed results, it can be hypothesized that the noteworthy differences in the leaching behaviour of RDF-I and RDF-G BA is either of a chemical origin, i.e. due to different mineral composition and solubility, and/or of a physical origin, i.e. kinetically hindered dissolution of mainly amorphous glassy phases. Equilibrium geochemical modelling was hence performed to further investigate the factors that lead to the lower leaching concentrations in the eluates of RDF-G BA as compared to those of RDF-I BA.

As a first start, a geochemical model was set-up independently from the measured leaching data. To this end, a limited set of minerals indicated in Table 2 as Dataset 1 , based solely on the mineralogical composition of the BA from XRD analysis (Fig. 1), was selected. In this list of phases also halite $(\mathrm{NaCl})$ and anhydrite $\left(\mathrm{CaSO}_{4}\right)$ were included, since they were assumed as plausible 
Table 2

Estimated amounts of mineral phases considered as a starting point for the modelling approaches (Datasets 1 and 2) applied for RDF-I BA and RDF-G BA. Results are reported in $\mathrm{g} / \mathrm{kg}$ of dry bottom ash.

\begin{tabular}{|c|c|c|c|c|c|}
\hline \multirow[t]{2}{*}{ Minerals } & \multirow[t]{2}{*}{ Chemical formula } & \multicolumn{2}{|l|}{ RDF-I BA } & \multicolumn{2}{|l|}{ RDF-G BA } \\
\hline & & DATASET 1 & DATASET 2 & DATASET 1 & DATASET 2 \\
\hline Calcite & $\mathrm{CaCO}_{3}$ & 167.2 & 167.2 & - & - \\
\hline Portlandite & $\mathrm{Ca}(\mathrm{OH})_{2}$ & 33.3 & 16.7 & - & - \\
\hline Hydrocalumite & $\mathrm{Ca}_{4} \mathrm{Al}_{2} \mathrm{Cl}_{2} \mathrm{O}_{6} 10 \mathrm{H}_{2} \mathrm{O}$ & 5.6 & 5.6 & - & - \\
\hline Quartz/Silica & $\mathrm{SiO}_{2}$ & 168.3 & 16.8 & 264.4 & 26.4 \\
\hline Gehlenite & $\mathrm{Ca}_{2} \mathrm{Al}_{2} \mathrm{SiO}_{7}$ & 219.4 & 109.7 & - & - \\
\hline Akermanite & $\mathrm{Ca}_{2} \mathrm{MgSi}_{2} \mathrm{O}_{7}$ & 54.5 & 27.3 & 136.4 & 68.2 \\
\hline Anorthite & $\mathrm{CaAl}_{2} \mathrm{Si}_{2} \mathrm{O}_{8}$ & 27.8 & 13.9 & - & - \\
\hline Amorphous $\mathrm{Al}(\mathrm{OH})_{3}$ & $\mathrm{Al}(\mathrm{OH})_{3}$ & - & - & 390 & 390 \\
\hline Di-calcium silicate & $\mathrm{Ca}_{2} \mathrm{SiO}_{4}$ & 155.1 & 77.5 & - & - \\
\hline Forsterite & $\mathrm{Mg}_{2} \mathrm{SiO}_{4}$ & 40.8 & 20.4 & - & - \\
\hline Hematite & $\mathrm{Fe}_{2} \mathrm{O}_{3}$ & 36.7 & - & - & - \\
\hline Magnetite & $\mathrm{Fe}_{3} \mathrm{O}_{4}$ & - & - & 9.3 & - \\
\hline Ferrihydrite & $\mathrm{Fe}(\mathrm{OH})_{3}$ & - & 24.6 & - & 4.3 \\
\hline Anhydrite & $\mathrm{CaSO}_{4}$ & 3.3 & 3.3 & 0.5 & 0.5 \\
\hline \multirow[t]{2}{*}{ Halite } & $\mathrm{NaCl}$ & 79 & 79 & 0.9 & 0.9 \\
\hline & Total & 991 & 559 & 801.5 & 490 \\
\hline
\end{tabular}

solubility controlling phases for $\mathrm{Na}$ and $\mathrm{SO}_{4}^{2-}$ for both types of BA on the basis of the findings of previous studies on MSWI BA (Mahieux et al., 2010; Bayuseno and Schmahl, 2010). Amorphous Al and silica were also taken into account in the model prediction for RDFG BA, based on the results of a previous study on MSW pyrolysis/ melting slag (Saffarzadeh et al., 2006). The amounts of each mineral phase, reported in Table 2 in mol/kg dry BA, were estimated so that the resulting concentrations of major components (reported in Table 3), calculated from the chemical formulas of the minerals, matched or were just below the respective measured total concentrations reported in Table 1 . The calcite content was independently estimated from the carbonate content of the samples.

Using the assumed set of minerals and the estimated total concentrations of major components, geochemical modelling was performed to predict the experimental leaching data of the BA samples. Measured concentrations and model predictions for these components are shown in Fig. 5 (Dataset 1).The modelled leaching curves obtained for $\mathrm{Ca}, \mathrm{Mg}$ and $\mathrm{Al}$ for RDF-I BA showed an adequate match with measured leaching data. However, the predicted ANC/ BNC curve for this type of BA increasingly overestimated the experimental behaviour for $\mathrm{pH}$ values below 11. In the case of the RDF-G $\mathrm{BA}$, Dataset 1 led to inadequate model predictions for $\mathrm{Ca}, \mathrm{Mg}, \mathrm{Si}$ and $\mathrm{Fe}$ concentrations. Furthermore, the predicted ANC/BNC proved also in this case higher than the measured data. Based on this important finding, it is plausible to infer that a lower amount of $\mathrm{pH}$ buffering mineral phases than those assumed in Dataset 1 was active in the leaching processes of both types of slag.

Table 3

Total amounts of major components for RDF-I BA and RDF-G BA in the modelling approaches (Datasets1 and 2) resulting from the estimated amounts of minerals given in Table 2). Results are reported in $\mathrm{g} / \mathrm{kg}$ of dry bottom ash.

\begin{tabular}{lccccc}
\hline \multirow{2}{*}{ Components } & \multicolumn{2}{l}{ RDF-I BA } & & \multicolumn{2}{l}{ RDF-G BA } \\
\cline { 2 - 3 } & DATASET 1 & DATASET 2 & & DATASET 1 & DATASET 2 \\
\hline $\mathrm{Ca}$ & 244 & 156.8 & & 40.3 & 20.2 \\
$\mathrm{Mg}$ & 19 & 9.7 & & 12.2 & 6.9 \\
$\mathrm{Si}$ & 151.5 & 44.4 & & 151.7 & 26.4 \\
$\mathrm{Al}$ & 49.1 & 24.8 & & 135 & 135 \\
$\mathrm{Fe}$ & 25.7 & 12.8 & & 6.7 & 2.2 \\
$\mathrm{SO}_{4}^{2-}$ & 2.3 & 2.3 & & 0.4 & 0.4 \\
$\mathrm{CO}_{3}^{2-}$ & 100.2 & 100.2 & & 0 & 0 \\
$\mathrm{Cl}^{-}$ & 48.6 & 48.6 & & 0.5 & 0.5 \\
$\mathrm{Na}$ & 31.1 & 31.1 & & 0.3 & 0.3 \\
\hline
\end{tabular}

Consequently, a second set of mineralogical data (Dataset 2) was hypothesized as shown in Table 2, and analyzed by geochemical modelling to try to obtain an optimal description of the buffering capacity and of the leachate composition of the two types of $B A$. In this dataset, the effect of a lower content of mineral phases presenting $\mathrm{pH}$ buffering capacity on the predicted ANC and leached concentrations was investigated. In addition, for some elements such as $\mathrm{Fe}$ and $\mathrm{Mg}$, different mineral phases were considered as illustrated in Table 2. For RDF-I BA, half of the amount of the main $\mathrm{pH}$ buffering minerals considered in Dataset 1 (portlandite, gehlenite, akermanite, forsterite and dicalcium silicate) excluding calcite, the amount of which was independently measured, and hydrocalumite, which was found to play only a minor role in the pH buffering capacity, was considered. Amorphous silica was considered as a more soluble surrogate mineral for quartz and its content was reduced by a factor of 10 . In the case of RDF-G BA, the amounts of akermanite and silica were similarly reduced by a factor of 2 and 10, respectively in Dataset 2, since only a small portion of the available concentrations of $\mathrm{Ca}, \mathrm{Al}, \mathrm{Mg}$ and $\mathrm{Si}$ seemed to be reactive in the leaching processes. Additional choices with respect to the mineral assemblages were also made in Dataset 2 for both types of BA to achieve a better description of leachate composition. In particular, for both samples, brucite $\left(\mathrm{Mg}(\mathrm{OH})_{2}\right)$ was allowed to precipitate as it was indicated as a solubility controlling phase for Mg leaching from MSWI BA (Dijkstra et al., 2006), whereas the leaching of $\mathrm{Fe}$ was assumed to be controlled by the precipitation of ferrydrite $\left(\mathrm{Fe}(\mathrm{OH})_{3}\right)$ instead of that of relatively insoluble phases such as hematite $\left(\mathrm{Fe}_{2} \mathrm{O}_{3}\right)$ and magnetite $\left(\mathrm{Fe}_{3} \mathrm{O}_{4}\right)$, following the work of Dijkstra et al. (2006).

Modelling results obtained considering Dataset 2 are also shown in Fig. 5 while Fig. 6 gives an overview of the amount of the mineralogical phases that were allowed to precipitate in Datasets 1 and 2 for both types of BA. The reduced amounts of $\mathrm{pH}$ buffering minerals, as well as the estimated availabilities of cations and anions assumed in Dataset 2 allowed a better fitting of the measured ANC/ BNC curve for both types of slags. For RDF-I BA, improved model descriptions were also obtained for $\mathrm{Ca}, \mathrm{Mg}$, $\mathrm{Al}$ and Fe based on the input parameters selected in Dataset 2. In addition, the leaching of $\mathrm{CO}_{3}^{2-}$, for which data were taken from Dijkstra et al. (2008) since a similar concentration at natural $\mathrm{pH}$ was found $(26 \mathrm{mg} / \mathrm{kg}$ at $\mathrm{pH}$ 12.3 ), was likely consistent with precipitation of calcite at $\mathrm{pH}>7$. For RDF-G BA, the leachate concentrations of Fe and Al were adequately predicted by the minerals selected in the second dataset. In both RDF-I and RDF-G BA, predicted concentrations of $\mathrm{SO}_{4}^{2-}$ were undersaturated with respect to anhydrite $\left(\mathrm{CaSO}_{4}\right)$. 

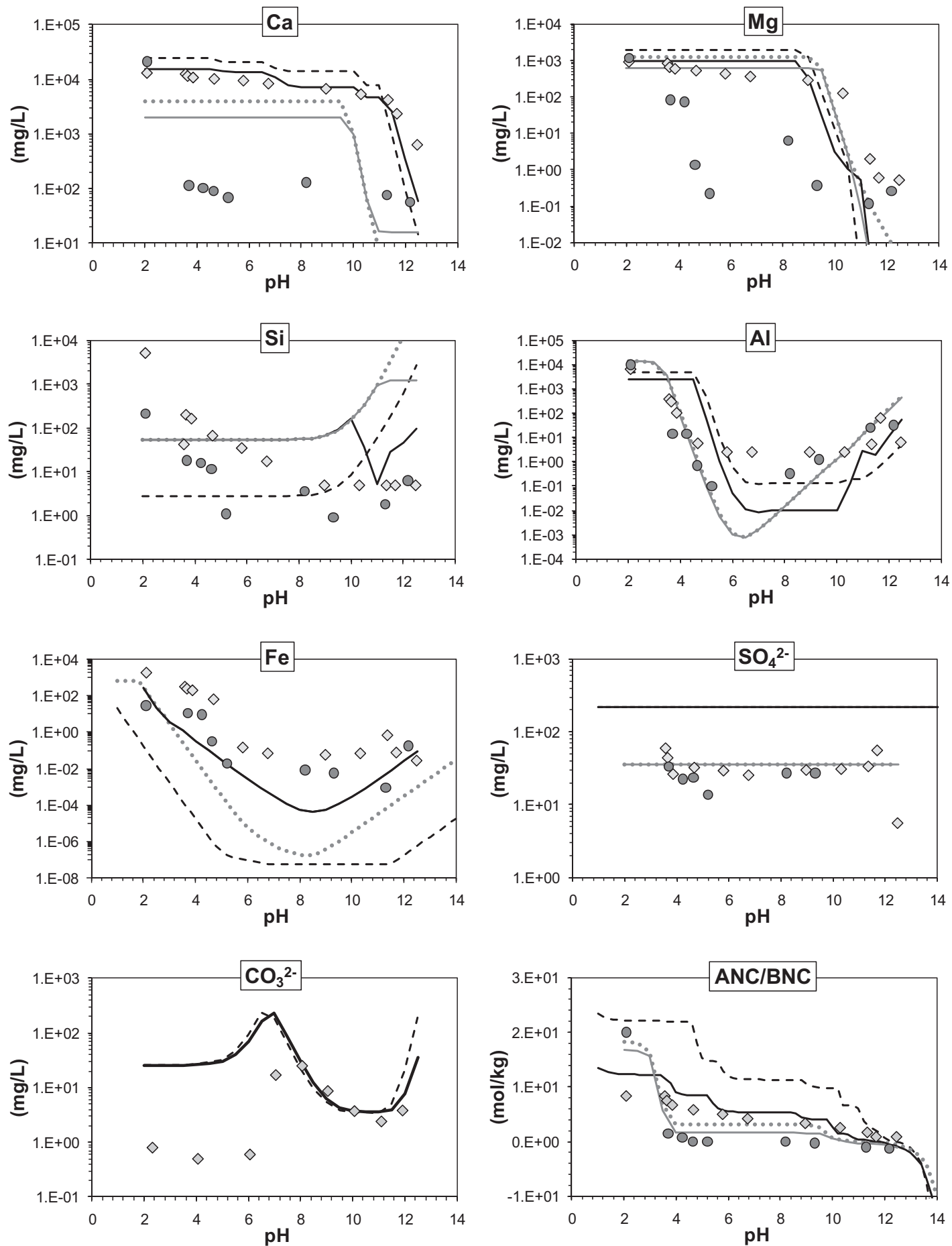

$$
\begin{array}{llll}
\diamond \text { RDF-IBA } & 0 & \text { RDF-GBA } & - \\
& \text { RDF-IBA RDF-IBA Dataset } 1
\end{array}
$$

Fig. 5. Leached concentrations and model predictions as a function of $\mathrm{pH}$ for $\mathrm{Ca}, \mathrm{Mg}, \mathrm{Si}, \mathrm{Al}, \mathrm{Fe}, \mathrm{SO}_{4}^{2-}$, $\mathrm{CO}_{3}^{2-}$ and $\mathrm{ANC} / \mathrm{BNC}$ from $\mathrm{RDF}-\mathrm{I} \mathrm{BA}$ and $\mathrm{RDF}-\mathrm{G} \mathrm{BA}$.

The inadequate match between the model curves and the experimental data for $\mathrm{Si}$, for the two types of BA considering both datasets, suggests that the precipitation/dissolution of different silicate phases than those considered in this work may occur in BA leachates (Meima and Comans, 1997). Adequate model fits were found for phases such as laumontite and wairakite for MSWI BA (Dijkstra et al., 2006, 2008) but the presence of these minerals in the RDF-I and RDF-G BA could not be independently confirmed.
It is however clear that $\mathrm{Si}$ showed a different $\mathrm{pH}$ dependent leaching behaviour than (amorphous) glass that is abundantly present in both types of BA samples. Even though the virtual absence of acid neutralizing capacity of the RDF-G BA sample was well matched by the model, the modelling predictions of $\mathrm{Ca}$ and $\mathrm{Mg}$ concentrations were still well above the measured data for this type of BA. Equilibrium with the selected mineral phases could not adequately explain in fact the exceptionally low leaching concentrations 
(a)

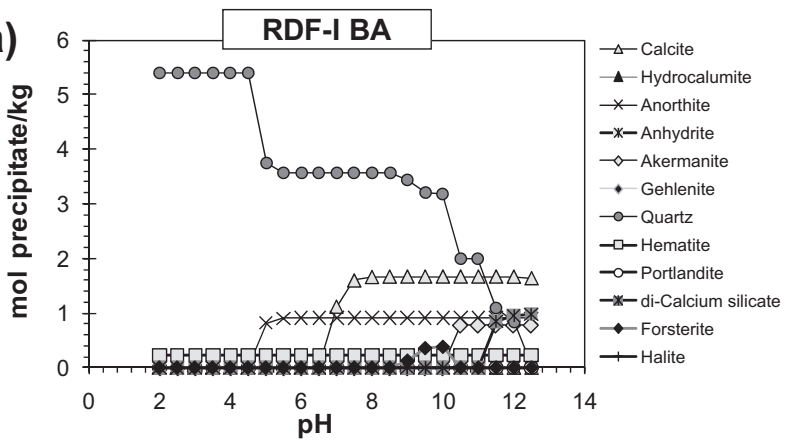

(c)

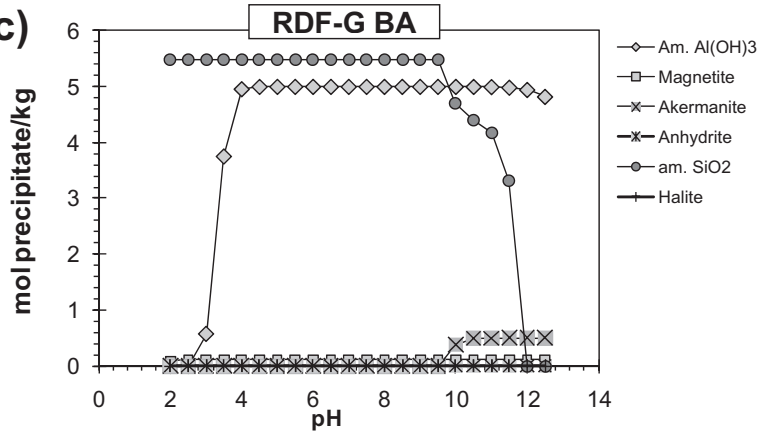

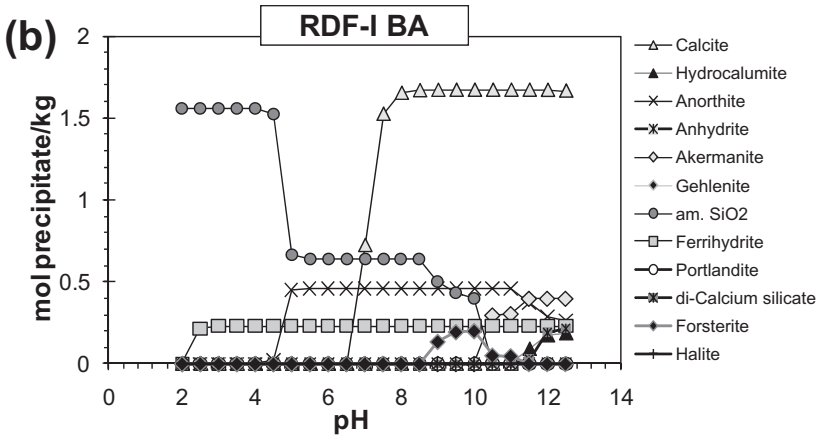

(d)

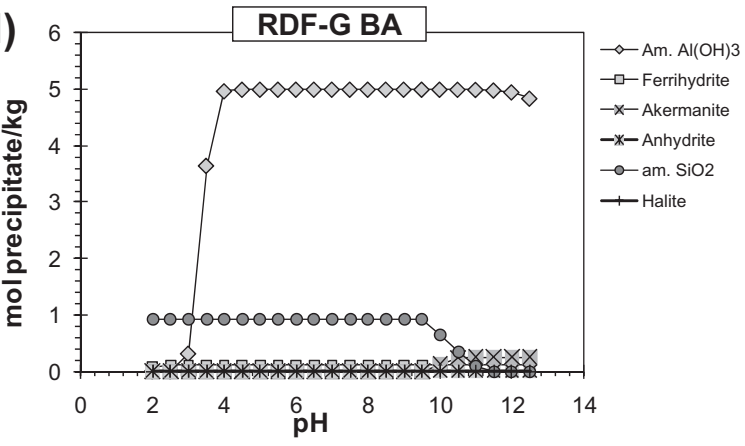

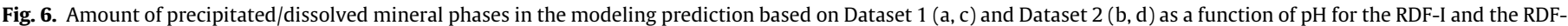
$\mathrm{G}$ BA samples. Results are expressed as $\mathrm{mol} / \mathrm{kg}$ BA.

determined for these elements. It must be noted that modelled mineral assemblages and mineral amounts, in particular those that have been inferred from the same measured data that were being modelled (e.g. ANC/BNC in Dataset 2), may suffer to some extent from non-uniqueness, i.e. different choices in mineral assemblages may provide similar model results as indicated also e.g. by Oreskes et al.(1994). Notwithstanding this intrinsic model uncertainty, it is reasonable to conclude that the extremely low buffering capacity and low leaching of major components determined for the RDF-G BA may be explained by the presence of significantly lower amounts of mineral phases available for leaching as compared to the other type of BA. In addition, it must be pointed out that, as previously mentioned, leaching test results can be influenced by kinetic effects related to the time interval for which these tests are carried out (e.g., Dijkstra et al., 2006) and this may be particularly true in the case of the glassy RDF-G BA matrix. Apparently, a large part of the major components was virtually fixed in the glass phases formed at high temperature.

\section{Conclusions and implications for further research}

The environmental properties of two specific types of bottom ash were investigated in this study: RDF incineration (RDF-I, operating temperature $850-1000^{\circ} \mathrm{C}$ ) and RDF gasification (RDF-G, operating temperature $1200-1400^{\circ} \mathrm{C}$ ) BA. The experimental results showed that the total content of major components was fairly similar for both types of bottom ash and possibly related to the characteristics of the RDF feedstock. However, significant differences in the contents of trace metals and salts were observed for the two BA samples, probably as a result of the different operating conditions (i.e. temperature) of the RDF thermal treatment technologies from which the BA originated. Consequently, the mineralogy of the RDF-I ash consisted of an assemblage of several crystalline phases while the RDF-G ash was mainly characterized by amorphous glassy phases.

Given the similar total Ca concentrations, differences in the $\mathrm{pH}$ values of the RDF-I BA (12.4) and the RDF-G BA (10.3) were related to the different $\mathrm{Ca}$ concentration values determined from the batch leaching tests (EN 12457-2). These results indicate that there was no direct correlation between the total content of elements such as Ca and their leaching concentrations that are mainly controlled by the solubility of the mineral phases to which these components are chemically bound in the slag matrix. On the other hand, a clear correlation between the bulk contents of non reactive salts-forming components (mainly $\mathrm{Cl}^{-}$) and their leaching concentrations was found for both samples. The leaching of some metals (e.g. Pb, $\mathrm{Zn}$ and $\mathrm{Cu}$ ) from the RDF-I BA at the native $\mathrm{pH}$ proved higher in comparison to RDF-G BA due to the different $\mathrm{pH}$ and mineralogy of the samples. In general, a more alkaline $\mathrm{pH}$ lead to higher solubility of these contaminants. Furthermore, differences in leaching of contaminants between the two types of slag may also be partly related to kinetic effects since the leaching availability of major components from the glassy matrix of the gasification BA proved limited compared to that of the incineration slag, at least within the timeframe of the performed tests. According to the compliance leaching test results, the RDF-G BA would abide the limits of the Italian legislation for reuse and the European acceptance criteria for inert waste landfilling. On the other hand, for RDF-I BA leaching concentrations of $\mathrm{Zn}, \mathrm{Pb}, \mathrm{Cu}, \mathrm{Cl}^{-}$and $\mathrm{Sb}$ exceeded the European acceptance criteria for inert waste landfilling, while complied with those set for non hazardous waste landfilling. However, the RDFG BA presented a significantly lower acid buffering capacity compared to the RDF-I sample. This finding is relevant as it is expected that the $\mathrm{pH}$ of RDF-G BA could be relatively quickly neutralized as a function of the conditions of the local environment pertaining to the selected disposal or reuse scenario. Different $\mathrm{pH}$ conditions could hence potentially lead to different conclusions regarding the environmental impact of RDF-G BA for a specific management option.

In this study a new geochemical modelling approach was followed using independent mineralogical information from XRD analysis and the measured total contents of the major components to predict the leaching behaviour, as well as the $\mathrm{pH}$ buffering capacity of the two types of slag. It was found that the combined 
analysis of the mineralogical characteristics and of the buffering capacity of the ash can be used to adequately obtain an independent estimate of both the type and the amount of minerals that contribute to the leaching process. This new modelling approach suggests that only a limited fraction of the minerals that control $\mathrm{pH}$, buffering capacity and major component leaching from the samples are available for leaching, at least on the time scale of the applied standard leaching tests. As such, the presented approach can contribute to extend knowledge regarding the types and amounts of minerals that control the leaching properties and $\mathrm{pH}$ buffering capacity of solid residues such as RDF incineration and gasification bottom ash.

Given the results of this study, it is believed important to investigate the $\mathrm{pH}$ development and the subsequent emission of contaminants from BA under field conditions (i.e. in contact with rainwater and atmospheric $\mathrm{CO}_{2}$ ) to further assess the environmental properties of these materials under specific application scenarios. In addition, leaching kinetics need to be investigated in more detail, particularly for RDF-G BA, as the glassy matrix of this material may limit the availability of metals for leaching.

\section{References}

Allison, J.D., Brown, D.S., Novo-Gradac, K.J., 1991. MINTEQA2/PRODEFA2, Geochemical assessment model for environmental systems: version 3.11 database and version 3.0 user's manual. U.S. Environmental Protection Agency, Athens, GA.

Baciocchi, R., Costa, G., Lategano, E., Marini, C., Polettini, A., Pomi, R., Postorino, P., Rocca, S., 2010. Accelerated carbonation of different size fractions of bottom ash from RDF incineration. Waste Manage. 30, 1310-1317.

Bayuseno, A.P., Schmahl, W.W., 2010. Understanding the chemical and mineralogical properties of the inorganic portion of MSWI bottom ash. Waste Manage. 30, 1509-1520.

Belgiorno, V., De Feo, G., Della Rocca, C., Napoli, R.M.A., 2003. Energy from gasification of solid wastes. Waste Manage. 23, 1-15.

Bosmans, A., Helsen, L., 2010. Energy from waste: review of thermochemical technologies for refuse derived fuel (RDF) treatment. Proceedings Venice 2010, Third International Symposium on Energy from Biomass and Waste, 8-11 November 2010, Venice (Italy).

Castaldi, M.J., Themelis, N.J., 2010. The case for increasing the global capacity for Waste to Energy (WTE). Waste Biomass Valor. 1, 91-105.

Chang, N., Wang, H.P., Huang, W.L., Lin, K.S., 1999. The assessment of reuse potential for municipal solid waste and refuse-derived fuel incineration ashes. Resour. Conserv. Recy. 25, 255-270.

Chimenos, J.M., Fèrnandez, A.I., Miralles, L., Segarra, M., Espiell, F., 2003. Short-term natural weathering of MSWI bottom ash as a function of particle size. Waste Manage. 23, 887-895.

Consonni, S., Giugliano, M., Grosso, M., 2005. Alternative strategies for energy recovery from municipal solid waste Part A: Mass and energy balances. Waste Manage. 25, 123-135.

Council of the European Union, 2003. Directive 2003/33/EC on the Landfill of Waste, Off. J. Eur. Union LII, 2003.

Dalai, A.K., Batta, N., Eswaramoorthi, I., Schoenau, G.J., 2009. Gasification of refuse derived fuel in a fixed bed reactor for syngas production. Waste Manage. 29, 252-258.

Dijkstra, J.J., van der Sloot, H.A., Comans, R.N.J., 2002. Process identification and model development of contaminant transport in MSWI bottom ash. Waste Manage. 22, 531-541.

Dijkstra, J.J., van der Sloot, H.A., Comans, R.N.J., 2006. The leaching of major and trace elements from MSWI bottom ash as a function of $\mathrm{pH}$ and time. Appl. Geochem. 21, 335-351.

Dijkstra, J.J., Meeussen, J.C.L., van der Sloot, H.A., Comans, R.N.J., 2008. A consistent geochemical modelling approach for the leaching and reactive transport of major and trace elements in MSWI bottom ash. Appl. Geochem. 23, 1544-1562.

Ecke, H., Aberg, A., 2006. Quantification of the effects of environmental leaching factors on emissions from bottom ash in road construction. Sci. Total Environ. $362,42-49$.

European Committee for Standardization (CEN), 2005. Technical specification (TS) 14429:2005 Characterization of waste - leaching behaviour tests - Influence of $\mathrm{pH}$ on leaching with intial acid/base. CEN Management Centre, Brussels.

Giugliano, M., Grosso, M., Rigamonti, L., 2008. Energy recovery from municipal waste: A case study for a middle-sized Italian district. Waste Manage. 28, 3950.

Gori, M., Pifferi, L., Sirini, P., 2011. Leaching behaviour of bottom ash from RDF hightemperature gasification plants. Waste Manage. 31, 1514-1521.

Haker, K., Kuchta, K., Krüger, J., 2010. Conception of a refuse derived fuel (RDF) incineration plant. Proceedings Venice 2010, Third International Symposium on Energy from Biomass and Waste, 8-11 November 2010, Venice (Italy).

Hyks, J., Astrup, T., 2009. Influence of operational conditions, waste input and ageing on contaminant leaching from waste incinerator bottom ash: A full-scale study. Chemosphere 76, 1178-1184.

Italian Institute for Environmental Protection and Research (ISPRA), 2009. Urban wastes report - edition 2009, (in Italian), 108/2010, ISBN 978-88-448-0430-5, ISPRA, Rome.

Italian Committee for Standardization (UNI), 2004. EN 12457-2:2004 Characterisation of waste-Leaching-Compliance test for leaching of granular waste materials and sludges-part 2: one stage batch test at a liquid to solid ratio of $10 \mathrm{l} / \mathrm{kg}$ for materials with particle size below $4 \mathrm{~mm}$ (without or with size reduction), UNI, Milan.

Italian Environmental Ministry (1998). Ministerial decree 05/02/1998. Individuazione dei rifiuti non pericolosi sottoposti alle procedure semplificate di recupero ai sensi degli articoli 31 e 33 del decreto legislativo 5 febbraio 1997, (in Italian), Suppl. Ord. G.U. 88 n. 22, as amended by Ministerial decree 05/04/ 2006, n. 186.

Jannelli, E., Minutillo, M., 2007. Simulation of the flue gas cleaning system of an RDF incineration power plant. Waste Manage. 27, 684-690.

Johnson, C.A., Brandenberger, S., Baccini, P., 1995. Acid neutralizing capacity of municipal solid waste incinerator bottom ash. Environ. Sci. Technol. 29, 142147.

Kosson, D.S., van der Sloot, H.A., Sanchez, F., Garrabrants, A.C., 2002. An integrated framework for evaluating leaching in waste management and utilization of secondary materials. Environ. Eng. Sci. 19, 159-204.

Lindsay, W.L., 1979. Chemical equilibria in soils. John Wiley \& Sons, New York.

Mahieux, P.Y., Aubert, J.E., Cyr, M., Coutand, M., Husson, B., 2010. Quantitative mineralogical composition of complex mineral wastes - Contribution of the Rietveld method. Waste Manage. 30, 378-388.

Meima, J.A., Comans, R.N.J., 1997. Geochemical modelling of weathering reactions in MSWI bottom ash. Environ. Sci. Technol. 31, 1269-1276.

Meussen, J.C.L., 2003. ORCHESTRA: an object-oriented framework for implementing chemical equilibrium models. Environ. Sci. Technol. 37, 1175-1182.

Onori, R., Polettini, A., Pomi, R., 2011. Mechanical properties and leaching modeling of activated incinerator bottom ash in Portland cement blends. Waste Manage. 31, 298-310.

Oreskes, N., Shrader-Frechette, K., Belitz, K., 1994. Verification, validation, and confirmation of numerical models in the Earth sciences. Science 263, 641-646.

Polettini, A., Pomi, R., 2004. The leaching behaviour of incinerator bottom ash as affected by accelerated ageing. J. Hazard. Mater. B113, 209-215.

Polettini A. (2009). State of the knowledge and research needs in bottom ash management. Proceedings Sardinia 2009, Twelfth International Waste Management and Landfill Symposium, 5-9 October 2009, S. Margherita di Pula, Cagliari (Italy).

Rendek, E., Ducom, G., Germain, P., 2007. Influence of waste input and combustion technology on MSWI bottom ash quality. Waste Manage. 27, 1403-1407.

Sivula, L., Ilander, A., Väisänen, A., Rintala, J., 2010. Weathering of gasification and grate bottom ash in anaerobic conditions. J. Hazard. Mater. 174, 344351.

Saffarzadeh, A., Shimaoka, T., Motomura, Y., Watanabe, K., 2006. Chemical and mineralogical evaluation of slag products derived from the pyrolysis/melting treatment of MSW. Waste Manage. 26, 1443-1452.

Travar, I., Lidelöw, S., Andreas, L., Tham, G., Lagerkvist, A., 2009. Assessing the environmental impact of ashes used in a landfill cover construction. Waste Manage. 29, 1336-1346. 